\title{
Form-priming effects in nonword naming
}

\author{
Iemke Horemans $^{\mathrm{a}}$ and Niels O. Schiller ${ }^{\mathrm{a}, \mathrm{b}, *}$ \\ a Department of Neurocognition, Faculty of Psychology, University of Maastricht, Maastricht, The Netherlands \\ ${ }^{\mathrm{b}}$ Max Planck Institute for Psycholinguistics, Nijmegen, The Netherlands
}

Accepted 4 December 2003

Available online 31 January 2004

\begin{abstract}
Form-priming effects from sublexical (syllabic or segmental) primes in masked priming can be accounted for in two ways. One is the sublexical pre-activation view according to which segments are pre-activated by the prime, and at the time the form-related target is to be produced, retrieval/assembly of those pre-activated segments is faster compared to an unrelated situation. However, it has also been argued that form-priming effects from sublexical primes might be due to lexical pre-activation. When the sublexical prime is presented, it activates all form-related words (i.e., cohorts) in the lexicon, necessarily including the form-related target, which - as a consequence - is produced faster than in the unrelated case. Note, however, that this lexical pre-activation account makes previous pre-lexical activation of segments necessary. This study reports a nonword naming experiment to investigate whether or not sublexical pre-activation is involved in masked form priming with sublexical primes. The results demonstrated a priming effect suggesting a nonlexical effect. However, this does not exclude an additional lexical component in form priming.
\end{abstract}

(C) 2003 Elsevier Inc. All rights reserved.

Keywords: Nonword naming; Masked priming; Phonological encoding; Visual word processing

\section{Introduction}

Visual word processing is concerned with the recognition and reading aloud of letter strings. Words can be read aloud or named by one of at least two different routes: either by accessing a word's lexical representation and retrieving information about the phonological form of a word from this representation or via grapheme-tophoneme conversion, i.e., assembling the pronunciation of a word segment by segment without contacting the lexicon (Coltheart, Rastle, Perry, Langdon, \& Ziegler, 2001). A central question in word naming is how formpriming effects arise. Forster and Davis (1991) showed that one important factor in the naming task is the onset of words. Targets in a masked priming paradigm yielded faster reaction times (RTs) when they matched in onset with the prime than when they did not. According to Forster and Davis (1991) this effect might be due to

\footnotetext{
${ }^{*}$ Corresponding author. Fax: +31-43-3882541.

E-mail addresses: n.schiller@psychology.unimaas.nl,niels.schiller@ mpi.nl (N.O. Schiller).
}

nonlexical response competition. Participants might have the tendency - on some trials - to subconsciously pronounce the prime upon presentation instead of the target. When the prime starts with a different segment than the target, response competition might occur when the pronunciation of the target is assembled. This is evidenced by so-called blending errors of the type ring (prime) and HOLE (target) become " $r O L E$ " (response). However, this account is contingent on the nonlexical grapheme-to-phoneme conversion route to work. When the pronunciation of words is lexically controlled, as is the case, e.g., for irregular words, response competition does not get the chance to exert any effect and no onset effect occurred (Forster \& Davis, 1991). Kinoshita (2000; see also Kinoshita \& Woollams, 2002) has recently replicated this onset effect.

The onset effect might also account for the difference between begin- and end-related prime-target pairs tested in a recent study conducted by Schiller (in press). Primes that matched the beginning of a target were significantly more effective than primes matching the end of a target. In fact, Schiller (in press) accounted for the formpriming effects found in his study by a combination of 
an onset effect and a segmental overlap effect. The segmental overlap effect is also a form-priming effect the magnitude of which depends on the amount of overlap in segments between the prime and the target (Schiller, 1998, 2000). Note that the onset effect and the segmental overlap effect have a different basis: While the onset effect is a low-level (articulatory) response preparation effect contingent on segmental overlap at the beginning of the target, the segmental overlap effect is a phonological pre-activation effect due to segmental overlap anywhere in the word. Recently, Schiller (in press) found additional evidence that it is not orthographic overlap that is important for the segmental overlap effect but phonological overlap between prime and target. What is still not entirely clear so far is how exactly the grapheme-to-phoneme mapping works although some preliminary suggestions have been made (Schiller, 2000; Schiller, Costa, \& Colomé, 2002; and especially Schiller \& Costa, submitted; see also Berent \& Perfetti, 1995).

One claim that has been made in the past is that the segmental overlap effect reported in Schiller (1998, 2000; Schiller et al., 2002) does not arise at a sublexical level as argued by Schiller and collaborators but rather at a lexical level. That is, form-priming effects obtained with masked primes consisting of sublexical strings such as segments or syllables are mainly due to lexical, not sublexical pre-activation. According to this lexical preactivation account, sublexical visually masked primes pre-activate cohorts of word forms in the lexicon that have the same (initial) segments instead of pre-activating only their segments. Thereby, the target also gets preactivated and can be named faster than when it was preceded by an unrelated prime. For instance, a consonant $(\mathrm{C})$-vowel(V) prime (e.g., pi) would pre-activate all words in the lexicon that start with the same $\mathrm{CV}$ sequence (e.g., pie, pike, pile, pilot, pineapple, etc.). By the time the target word (e.g., pilot or a picture of a pilot) is to be named, the target has already been preactivated and can be produced faster than when preceded by an unrelated prime. Schiller (2000) demonstrated that an effect of cohort size, i.e., the number of words starting with the same segments, would support the lexical account. The number of words, i.e., the cohort, activated by a prime becomes smaller when the prime gets longer. Hence, the amount of pre-activation provided by the prime (e.g., CVC) is distributed across fewer targets than when the prime is shorter (e.g., CV) and the set of targets in the cohort is greater. Therefore, long primes (e.g., CVC) yield stronger priming effects than short primes (e.g., CV).

However, Ferrand, Segui, and Grainger (1996, Experiment 2) reported a sublexical priming effect with nonword targets in French. They had French participants naming bisyllabic nonwords with a $\mathrm{CV}$ or CVC first-syllable structure preceded by visual $\mathrm{CV}$ or $\mathrm{CVC}$ primes. The result of that experiment was a syllable priming effect, i.e., $\mathrm{CV}$ targets were named faster when preceded by $\mathrm{CV}$ primes than by $\mathrm{CVC}$ primes and for CVC targets the situation was reversed. According to Ferrand et al. (1996), their study supports the hypothesis that syllable units are functional units in the production of speech. The outcome of their Experiment 2 seemed to prove that form-priming effects in naming tasks must at least partially be due to sublexical activation in the phonological lexicon. Unfortunately, however, the syllabic priming effect reported by Ferrand et al. (1996) was demonstrated not to be reliable (Schiller, 1998, 2000) - not even in French (Brandt, Rey, \& Peereman, 2003; Bonin, Peereman, \& Schiller reported in Schiller et al., 2002). Therefore, it is not entirely clear what the results of the nonword experiment of Ferrand et al. (1996) might really tell us if the syllable priming effect is not reliable. Furthermore, to our knowledge nonwords have never been tested in a naming task in Dutch. To demonstrate that formpriming effects for nonwords can be obtained using the masked priming paradigm in Dutch thereby showing that those effects must be due to sublexical pre-activation (since nonwords do not have a lexical representation), the following experiment was carried out.

\section{Experiment: Nonword naming with begin- and end- related masked primes}

In order to shed light on the question of whether formpriming effects have a sublexical basis, a nonword naming experiment was carried out. Participants saw a nonword on a computer screen and were requested to read it aloud as fast as they could while trying to avoid errors. If segmental (nonlexical) pre-activation is involved in assembling the naming response for nonwords, we should find form-priming effects from sublexical primes in a nonword naming experiment. If form-priming effects were entirely due to lexical pre-activation, no form-priming effects are expected since nonwords are not stored in the lexicon.

\subsection{Method}

\subsubsection{Participants}

Fifteen undergraduate students from the University of Nijmegen took part in the Experiment. All were native speakers of Dutch and had normal or corrected-tonormal vision. They were paid for their participation in the experiment.

\subsubsection{Materials}

The materials consisted of 45 phonotactically legal nonwords. The nonwords were constructed by recombining the syllables of 45 bisyllabic Dutch words. The complete list of stimuli can be found in Appendix A. 


\subsubsection{Procedure}

The procedure was broadly similar to the one used in Schiller (1998, 2000). Participants were tested individually in a dimly lit, soundproof room. They were seated about $60 \mathrm{~cm}$ from a computer screen. Target words appeared as white capital letters in a nonproportional font (Courier; 28 pts) on a black screen and remained in view until a response was given or $2000 \mathrm{~ms}$ maximally. Before the presentation of a target, a fixation point appeared for $500 \mathrm{~ms}$ in the middle of the screen on which participants were asked to fixate. Then a row of hash marks (\#'s) that matched the length in letters of the longest nonword target (eight characters) appeared for $500 \mathrm{~ms}$ as a forward mask and replaced the fixation point. Immediately afterwards, the prime was presented in lower case for $50 \mathrm{~ms}$ (three screen refresh cycles), followed by a backward mask for $17 \mathrm{~ms}$ (one screen refresh cycle), which was identical to the forward mask. The target immediately replaced the backward mask. In earlier studies, it was formally assessed that under these masking conditions participants are generally not able to recognize the primes (see prime visibility tests reported in Schiller, 1998, p. 489; Schiller, 2000, p. 517). Sometimes, however, participants are able to identify single letters from the primes. The current experiment was run in the same laboratory using the same equipment and prime exposure duration as the experiments reported in the Schiller (1998) study. All stimuli were centered on the screen. Added to the prime were percent signs ("\%") until the prime matched the length of the masks. This procedure was used to avoid additional flickering on the screen due to presentation of stimuli different in length. Naming latencies (RTs) were measured with a voice key from target onset. Trial sequencing was controlled by NESU (Nijmegen Experimental Set-Up). The presence of a prime was not mentioned to the participants. Participants were instructed to name the target as fast as possible while avoiding errors. When a response was given, the next trial started $1000 \mathrm{~ms}$ later. Materials were blocked into sets of 25 items, and after each block the mean RTs were displayed on the screen. Participants were asked to write down their mean RTs. This had the purpose to speed participants up.

\subsubsection{Design}

Across the experiment, each target (e.g., KATROEN) was preceded by five primes: a first-syllable (e.g., ka\%\%\%\%\%\%-KATROEN), a second-syllable (e.g., $\% \%$ troen $\%$-KATROEN), a first-segment or onset (e.g., $\mathrm{k} \% \% \% \% \% \%$-KATROEN), a first-segment plus secondsyllable (e.g., k\%troen\%-KATROEN), and an unrelated control prime (e.g., \%\%\%\%\%\%\%\%-KATROEN). The firstsegment prime was included to check whether or not an onset effect can be obtained. The first-syllable, secondsyllable, and first-segment plus second-syllable primes were included to investigate whether or not form priming can be obtained beyond the onset, and the unrelated control condition was included for comparison purposes. The total of 225 trials ( 45 nonwords $\times 5$ priming conditions) was divided into nine blocks of 25 trials. In each block, there was an equal number of priming conditions. Blocks were randomized individually for each participant and the order of block presentation was counterbalanced.

\subsection{Results}

Naming latencies shorter than $300 \mathrm{~ms}$ and longer than $1000 \mathrm{~ms}$ were counted as outliers $(0.4 \%$ of the data) and excluded from the RT analyses. The mean naming latencies and error rates are summarized in Table 1. ANOVAs were run with Prime Type as independent variable. Separate analyses were carried out with participants $\left(F_{1}\right)$ and items $\left(F_{2}\right)$ as random variables.

\subsubsection{Error rates}

The overall error rate was $4.4 \%$. The main effect of Prime Type was not significant $\left(F_{1}(4,56)=1.06, M S_{\mathrm{e}}=\right.$ 1.87 , n.s.; $F_{2}(4,176)=1.30, M S_{\mathrm{e}}=0.51$, n.s. $)$.

\subsubsection{Naming latencies}

The main effect of Prime Type was significant $\left(F_{1}(4,56)=15.86, M S_{\mathrm{e}}=81.40, p<.01 ; F_{2}(4,176)=\right.$ 14.73, $\left.M S_{\mathrm{e}}=278.36, p<.01\right)$. Naming latencies were slowest in the control condition $(477 \mathrm{~ms})$. Compared to this condition, there were small priming effects both in the first-segment condition (e.g., k\%\%\%\%\%\%\%-KATROEN; $467 \mathrm{~ms}$ ) and in the second-syllable condition (e.g., $\% \%$ troen\%-KATROEN; $468 \mathrm{~ms}$ ). These priming effects were significant (Bonferroni adjusted $\alpha$-level $=.005$ ) by items and marginally significant by participants $\left(t_{1}(14)=2.35, S D=15.54, p<.05 ; t_{2}(44)=3.12, S D=\right.$ $21.85 ; p<.005)$ and $\left(t_{1}(14)=2.36, S D=14.07 ; p<.05\right.$; $\left.t_{2}(44)=3.00, S D=21.48 ; p<.005\right)$, respectively. The first-syllable condition (e.g., ka\%\%\%\%\%\%-KATROEN; $455 \mathrm{~ms}$ ) was not only significantly faster than the control condition $\left(t_{1}(14)=7.46, S D=11.07, p<.005 ; t_{2}(44)=\right.$ $5.85, S D=26.08 ; p<.005)$, but also reliably faster than the first-segment condition $\left(t_{1}(14)=3.94, S D=11.69\right.$, $\left.p<.005 ; t_{2}(44)=3.69, S D=22.95 ; p<.005\right)$. Also, the

Table 1

Mean naming latencies (in milliseconds) and percentage errors (in parentheses) in the experiment

\begin{tabular}{lll}
\hline Condition & Example & Mean RT \\
\hline First-syllable & $(\% \% \mathrm{ka} \% \% \% \% \%$-KATROEN) & $455(4.3)$ \\
First-segment & $(\% \% \mathrm{k} \% \% \% \% \%$-KATROEN) & $467(4.9)$ \\
$\begin{array}{l}\text { First-segment } \\
\text { plus second- }\end{array}$ & $(\% \% \mathrm{k} \%$ troen\%-KATROEN) & $455(3.7)$ \\
$\quad$ syllable & & \\
Second-syllable & $(\% \% \% \%$ troen\%-KATROEN) & $468(3.6)$ \\
Control & $(\% \% \% \% \% \% \% \%$-KATROEN) & $477(5.5)$ \\
\hline
\end{tabular}


first-segment plus second-syllable condition (e.g., k\%troen\%-KATROEN; $455 \mathrm{~ms}$ ) was $12 \mathrm{~ms}$ faster than the first-segment condition $\left(t_{1}(14)=4.12, S D=11.60\right.$, $\left.p<.005 ; t_{2}(44)=3.27, S D=24.26 ; p<.005\right)$. These two conditions demonstrate form priming beyond the onset. Furthermore, the first-syllable condition $(455 \mathrm{~ms})$ yielded significantly shorter naming latencies than the second-syllable condition $\left(468 \mathrm{~ms} ; t_{1}(14)=3.99, S D=\right.$ $\left.12.36, p<.005 ; t_{2}(44)=3.89, S D=22.70 ; p<.005\right)$. This replicates the advantage of initial over final overlap conditions and underlines the importance of the position of the overlap. In a related study, Schiller (in press) suggested that this advantage might be due to an onset effect. In priming conditions that match the onset of the target, starting to name the prime instead of the target on some trials would be advantageous compared to conditions in which the onsets do not match. However, that cannot be the whole story because the first-syllable and the first-segment-plus-second-syllable conditions are not only faster than the control condition but also faster than the onset condition. This apparent discrepancy will be taken up in the following section.

\subsection{Discussion}

This experiment showed that form-priming effects in naming could be obtained with Dutch nonwords. This demonstrates a sublexical basis of the form-priming effect. Note that the magnitude of the effects in the present study is comparable to the priming effects of a study using existing word targets and similar primes (Schiller, in press). Of course, on the basis of the present data we cannot completely rule out lexical activation in case existing words are used as targets, but the fact that even second syllable primes yielded a form-priming effect undermines the cohort activation account to some extent since it would be unclear how a second syllable prime could pre-activate a lexical cohort including the target.

An advantage of first over second syllable primes appeared suggesting that this advantage is due to the position of overlap (initial vs. final) between prime and target. One possible account for the result that the firstsyllable condition yielded a larger priming effect than the second-syllable condition is that participants sometimes began to speak before having encoded the whole word. This led to faster RTs in the first-syllable condition than in the second-syllable or the control condition because the first segment of the prime matched that of the target. In contrast, in the second-syllable condition, this was not the case. Therefore, initial syllables are more efficient primes than final syllables. This account is similar to response competition accounts of onset effects (Forster \& Davis, 1991).

However, there is also evidence for a segmental overlap effect, i.e., a general form-priming effect, the magnitude of which is contingent upon the amount of segmental overlap between prime and target. First-syllable primes yielded on average more priming than first-segment primes and first-segment plus second-syllable primes yielded more priming than either first-segment primes or second-syllable primes. This is difficult to reconcile with an onset effect because when an onset effect occurs, there cannot be any form priming from the final part of the target, unless participants always wait until they have encoded the whole word. Importantly, the amount of segmental overlap and the position of segmental overlap (initial vs. noninitial) play a crucial rule for the magnitude of the form-priming effect in masked priming.

Interestingly, the experiment reported in this paper yielded a different outcome than the nonword naming experiment reported by Ferrand et al. (1996). We obtained form-priming effects also for primes that included less than the first syllable of the target (e.g., first-segment primes). This supports once more the view that the syllable priming effect reported by Ferrand et al. (1996) is not reliable (see also Brand et al., 2003; Schiller, 1998, 2000; Schiller et al., 2002) and that even sublexical units of segmental (sub-syllabic) size can be pre-activated by visually masked primes in the naming task.

\section{Acknowledgments}

The research of Niels O. Schiller was supported by a fellowship from the Dutch Royal Academy of Arts and Sciences (Koninklijke Nederlandse Akademie voor Wetenschappen; KNAW). The experiment reported in this paper was carried out at the Max Planck Institute for Psycholinguistics in Nijmegen, The Netherlands. The authors thank Frouke Hermens for running the experiment and Ken Forster for helpful discussion.

\section{Appendix A}

Stimulus materials from the experiment

\begin{tabular}{lll}
\hline \multicolumn{2}{l}{ Target nonwords } & \\
\hline anweer & tracseel & haguin \\
anzem & tromstel & gemer \\
batel & katroen & motaar \\
doltus & tijbot & magtel \\
gimeel & vartel & masto \\
fobus & vlinster & kubriek \\
ranijn & stemter & pleikel \\
cirneet & borpel & sitel \\
beitor & pinker & tader \\
begaar & mijken & kalen \\
ronaan & worha & kotel \\
betor & cacpet & keker \\
halfijn & beto & penter \\
sleuket & taker & moger \\
spijfel & cinon & raker \\
\hline
\end{tabular}




\section{References}

Berent, I., \& Perfetti, C. A. (1995). A rose is a REEZ: The two-cycles model of phonological assembly in reading English. Psychological Review, 102, 146-184.

Brandt, M., Rey, A., \& Peereman, R. (2003). Where is the syllable priming effect in visual word recognition? Journal of Memory and Language, 48, 435-443.

Coltheart, M., Rastle, K., Perry, C., Langdon, R., \& Ziegler, J. (2001). DRC: A dual route cascaded model of visual word recognition and reading aloud. Psychological Review, 108, 204-256.

Ferrand, L., Segui, J., \& Grainger, J. (1996). Masked priming of word and picture naming: The role of syllabic units. Journal of Memory and Language, 35, 708-723.

Forster, K. I., \& Davis, C. (1991). The density constraint on formpriming in the naming task: Interference effects from a masked prime. Journal of Memory and Language, 30, 1-25.

Kinoshita, S. (2000). The left-to-right nature of the masked onset effect in naming. Psychonomic Bulletin and Reviews, 7, 133-141.
Kinoshita, S., \& Woollams, A. (2002). The masked onset priming effect in naming: Computation of phonology or speech-planning. Memory \& Cognition, 30, 237-245.

Schiller, N. O. (1998). The effect of visually masked syllable primes on the naming latencies of words and pictures. Journal of Memory and Language, 39, 484-507.

Schiller, N. O. (2000). Single word production in English: The role of subsyllabic units during phonological encoding. Journal of Experimental Psychology: Learning, Memory, and Cognition, 26, 512528

Schiller, N. O. (in press). The onset effect in word and picture naming. Journal of Memory and Language.

Schiller, N. O., \& Costa, A. (submitted). The role of the syllable in phonological encoding: Evidence from masked priming?.

Schiller, N. O., Costa, A., \& Colomé, A. (2002). Phonological encoding of single words: In search of the lost syllable. In C. Gussenhoven \& N. Warner (Eds.), Papers in laboratory phonology (Vol. 7, pp. 35-59). Berlin: Mouton de Gruyter. 